\title{
Body Mass Index, Quality of Life and Migraine in Students
}

\section{Castro K ${ }^{1}$, Rockett FC ${ }^{1,2}$, Klein LS ${ }^{1}$, Parizotti LS ${ }^{1}$, Perla AS ${ }^{3}$ and Perry IS $S^{\star 1,4}$}

${ }^{1}$ Food and Nutrition Research Center- Hospital de Clínicas de Porto Alegre/Universidade Federal do Rio Grande do Sul, Porto Alegre, Rio Grande do Sul, Brazil

${ }^{2}$ Postgraduate Program in Medicine: Medical Sciences, Universidade Federal do Rio Grande do Sul, Porto Alegre, Brazil

${ }^{3}$ Hospital São José, Complexo Hospitalar Irmandade de Misericórdia de Porto Alegre, Rio Grande do Sul, Brazil ${ }^{4}$ Universidade do Extremo Sul Catarinense (UNESC), Unidade Acadêmica de Ciências da Saúde, Criciúma, Santa Catarina, Brazil

${ }^{*}$ Corresponding author: Perry IS, Hospital de Clínicas de Porto Alegre, Centro de Pesquisa Clínica - Prédio 21- Sala 21307, Rua Ramiro Barcelos, 2350, Porto Alegre - RS, Fax: +55 513359 7674, Tel: +55 513359 6326, E-mail: atputp@gmail.com

Citation: Castro K, Rockett FC, Klein, Parizotti, Perla AS, et al. (2014) Body Mass Index, Quality of Life and Migraine in Students. J Nutr Health Sci 1(2): 205. doi: 10.15744/2393-9060.1.205

Received Date: August 04, 2014 Accepted Date: August 09, 2014 Published Date: August 26, 2014

\begin{abstract}
Migraine is reported globally with a higher prevalence in students. The present study aims to evaluate the association between nutritional status, quality of life (QL) and characteristics of migraine.

A cross-sectional study. Headache characteristics, level of disability caused by migraine crises (Pediatric Migraine Disability Assessment - PedMIDAS) and QL (Pediatric Quality of Life Inventory- PedsQL) were assessed. Anthropometric variables were also measured.

Data were collected from 98 students with a mean age of $11.2 \pm 1.7$ years. Migraine had the highest prevalence (54.8\%). The average Body Mass Index (BMI) of the total sample was $20.0 \pm 3.8 \mathrm{~kg} / \mathrm{m}^{2}$, and among students with migraine and students with tension headache, the average BMIs were $20.4 \pm 4.0$ and $19.5 \pm 3.4 \mathrm{~kg} / \mathrm{m}^{2}$, respectively $(\mathrm{p}=0.264$, Student's $t$-test). Around $47.5 \%$ from migraineurs were overweight or obese. Regarding QL, the average total score in students with migraine was $74.4 \pm 12.4$, with no differences observed among normal weight, overweight or obese students, and no correlation between the scores of the PedsQL and BMI ( $\mathrm{r}=-0.182, \mathrm{p}=0.165$, Pearson correlation coefficient) was observed. There was a high percentage of overweight students with migraine. Analyses show no associations between the nutritional status, frequency, severity, disability caused by crises, or QL.

Keywords: Child; Teenager; Headache; Anthropometry; Quality of life

List of Abbreviations: QL- Quality of life; PedMIDAS- Pediatric Migraine Disability Assessment; PedsQL- Pediatric Quality of Life Inventory; BMI-Body Mass Index; IBGE- Instituto Brasileiro de Geografia e Estatística; ABEP- Associação Brasileira de Empresas de Pesquisa; MIG- Migraine; TH- Tension headache
\end{abstract}

\section{Introduction}

The main primary headache among children and adolescents is migraine, a neurological disease characterized by a high prevalence of recurrent, moderate to severe pain [1] leading to decreased quality of life (QL) [2].

Migraine is considered to be one of the most prevalent forms of headache. In childhood and adolescence, migraine is reported globally. In a systematic review Abu-Arafeh et al. 2010 [3] showed overall prevalence of migraine in children and adolescents around $7.7 \%$. Before the age of 7, boys with migraine outnumber girls. However, boys are equally as likely as girls to experience migraine between the ages of 7 to 11 years [4]. With puberty, there is an increased prevalence of migraine in females, suggesting a role for female sex hormones in the expression of this headache [5]. Migraine crises in children can be shorter and more frequent than those in adults [1]. This disease in childhood has a high risk of developing into a chronic and persistent form in adulthood [6].

Migraine has also been associated with obesity. Both are important clinical problems that can significantly affect QL, health and individual well-being. Hershey et al. (2008) [7] investigated the effect of weight loss on the characteristics of headache in children and adolescents, and in those who were overweight, weight loss contributed to a reduction in pain over time.

In children, as well as in adults, an association between the presence of stress and migraine crises has been described, whereas teenage girls are apparently more susceptible [8]. Children who experience migraine often require a treatment strategy that includes changes in lifestyle [9].

Considering the impacts of this morbidity on the QL of children and adolescents, this study, which aims to evaluate the association between nutritional status, QL and characteristics of migraine in students, could contribute to clarify some of these aspects. 


\section{Methods}

A cross-sectional study was performed using students of both genders, aged 7 to 14 years, who reported headache and whose parents or guardians agreed to participate in the study and signed a consent form. Data collection occurred in 2012 in public and private schools in Porto Alegre, Rio Grande do Sul, Brazil, which were chosen for convenience. We excluded students that were unable to answer the questionnaires or be assessed anthropometrically.

Sociodemographic variables (age, gender) and clinical background (classification of headache, headache frequency, headache intensity, disability generated by migraine crises) were collected through interviews. The evaluation of the purchasing power of the participants was performed using the Economic Classification Criterion Brazil [10]. According to the score obtained, the household income, and thus purchasing power, could be estimated, and each household could be classified it into one of five groups, A to E (A representing the richest stratum of society and E, the poorest).

The students answered a questionnaire that concerned the characteristics of headache. This questionnaire was then evaluated by a neurologist according to the criteria defined by the International Headache Society [1]. For the assessment of disability generated by crisis, the Pediatric Migraine Disability Assessment (PedMIDAS) [11] was used. This questionnaire contains questions about the last three months relate to the impact of headache on school performance, at home and the final two questions relate to social / sports function. QL was assessed using the Pediatric Quality of Life Inventory (PedsQL), which has 23 items related to pediatric health domains, covering physical, emotional, social and school aspects [12,13].

Previously trained nutritionists performed all measurements and the methods were standardized. The anthropometric variables considered were as follows: weight $(\mathrm{kg})$; height $(\mathrm{cm})$; body mass index $(\mathrm{BMI})$; and the classification of nutritional status, according to the Z-score (weight for age, weight for height, BMI-for-age, and height for age) [14], with the help of the software AnthroPlus v. 1.0.4 [15]. Weight was assessed using a Tanita ${ }^{\circledR}$ digital electronic scale (Tanita Corporation, Tokyo, Japan), with a capacity of $150 \mathrm{~kg}$ and sensitivity of $50 \mathrm{~g}$. The weighing protocol followed previously published guidelines [14]. The height measurement was made using a Sanny ${ }^{\oplus}$ vertical stadiometer (American Medical Brazil, SBC, SP), with a length of $2.1 \mathrm{~m}$, divided into $\mathrm{cm}$ and subdivided into $\mathrm{mm}$.

Statistical analyses were performed using the SPSS 18.0 software. Categorical data were expressed as absolute frequencies and percentages, and continuous variables were collected as the means and standard deviations or the median and interquartile ranges. For association and correlation between variables, the non-parametric Chi-square and Pearson Correlation Coefficient tests were used, respectively; to compare means, ANOVA or Student's t-test; to compare medians the Mann-Whitney test. A $p$ value $<0.05$ was considered to be statistically significant.

The study was approved by the Ethics Committee of the Universidade Federal do Rio Grande do Sul under protocol number 20425 and complied with the Resolution No. 196 of 10/10/1996 of the National Health Council.

\section{Results}

Data were collected from 98 students who reported headache in the last three months. Participants included 61 girls and 37 boys, with a mean age of $11.2 \pm 1.7$ years, registered in public and private school systems ( $54.1 \%$ and $45.9 \%$, respectively). The predominant economic classification was class B (52.0\%). Considering headache types, migraine prevalence was $63 \%(\mathrm{n}=62)$ and tension headache, $36.7 \%(\mathrm{n}=36)$. There were no associations found between the types of headache and sex, age, school system, schedule of classes or socioeconomic status of the students (Table 1).

According to the BMI measurements $59.4 \%$ of the students were classified as normal weight, $24.0 \%$ overweight and $16.7 \%$ were obese. The average BMI of the total sample was $20.0 \pm 3.8 \mathrm{~kg} / \mathrm{m}^{2}$. Among students with migraine and students with tension headache, the average BMIs were $20.4 \pm 4.0 \mathrm{~kg} / \mathrm{m}^{2}$ and $19.5 \pm 3.4 \mathrm{~kg} / \mathrm{m}^{2}$, respectively $(\mathrm{p}=0.264$, Student's $t$-test). Both groups, on average, were within the parameters of normality [14].

Considering only the students with migraine, $47.5 \%$ were overweight (encompassing both the overweight and obese categories), and $18.0 \%$ were classified as obese. The other $52.5 \%$ were normal weight.

Concerning the incapacity generated by migraine attacks [11], most students scored at PedMIDAS level $1(67.2 \% ; n=41)$. Fifteen migraineurs (24.6\%) were in level 2, four (6.6\%) in level 3 and one (1.6\%) in level 4.

The number of students who experienced migraine crises in the past three months had a median value of 6 (P25-75: 3-12), and there were no correlations between the number or severity of these crisis and BMI mean $(r=0.061, p=0.644 ; r=0.048, p=0.737$, respectively, Pearson correlation coefficient). However, there was a tendency towards correlation between the number and severity of these attacks ( $\mathrm{r}=0.261, \mathrm{p}=0.062$, Pearson correlation coefficient).

Table 2 presents the characteristics of migraine (frequency, severity and disability generated by crises), according to BMI classification. There were no differences in the number of migraine crises among the BMI classification, and there were also no associations between migraine severity or the level of disability incurred by migraine and nutritional status. 


\begin{tabular}{|c|c|c|c|c|}
\hline & $\begin{array}{c}\text { MIG } \\
\text { (n and \%) }\end{array}$ & $\begin{array}{c}\text { TH } \\
\text { (n and \%) }\end{array}$ & $\begin{array}{c}\text { Total } \\
\text { (n and \%) }\end{array}$ & $\begin{array}{c}\mathbf{P} \\
\text { Test } \chi^{2}\end{array}$ \\
\hline \multicolumn{5}{|l|}{ Age } \\
\hline 7 - 9 years & $16(25.8 \%)$ & $9(25.0 \%)$ & $25(25.5 \%)$ & \multirow{2}{*}{0.930} \\
\hline $10-14$ years & $46(74.2 \%)$ & $17(75.0 \%)$ & $73(74.5 \%)$ & \\
\hline \multicolumn{5}{|l|}{ Gender } \\
\hline Female & $37(59.7 \%)$ & $24(66.7 \%)$ & $61(62.2 \%)$ & \multirow{2}{*}{0.491} \\
\hline Male & $25(40.3 \%)$ & $12(33.3 \%)$ & $37(37.8 \%)$ & \\
\hline \multicolumn{5}{|c|}{ Education System } \\
\hline Public & $36(58.1 \%)$ & $19(52.8 \%)$ & $53(54.1 \%)$ & \multirow{2}{*}{0.299} \\
\hline Private & $26(41.9 \%)$ & $17(47.2 \%)$ & $45(45.9 \%)$ & \\
\hline \multicolumn{5}{|l|}{ Schedule Class } \\
\hline Morning & $30(48.4 \%)$ & $23(63.9 \%)$ & $53(54.1 \%)$ & \multirow{2}{*}{0.138} \\
\hline Afternoon & $32(51.6 \%)$ & $32(51.6 \%)$ & $45(45.9 \%)$ & \\
\hline \multicolumn{5}{|l|}{ ABEP } \\
\hline A & $14(22.6 \%)$ & $9(25.0 \%)$ & $23(23.5 \%)$ & \multirow{2}{*}{0.913} \\
\hline B & $32(51.6 \%)$ & $19(52.8 \%)$ & $51(52.0 \%)$ & \\
\hline $\mathrm{C}$ & $16(25.8 \%)$ & $8(22.2 \%)$ & $24(24.5 \%)$ & \\
\hline
\end{tabular}

ABEP - Associação Brasileira de Empresas de Pesquisa; MIG - migraine; TH - tension headache

Table 1: Characteristics of the sample of students with headache

Regarding QL, the average total score in migraineurs was $74.4 \pm 12.4$, with no observed difference among normal weight, overweight and obese students (Table 2). There was also no correlation found between the scores of the PedsQL [12,13] and BMI $(\mathrm{r}=-0.182, \mathrm{p}=0.165$, Pearson correlation coefficient).

\begin{tabular}{|c|c|c|c|c|}
\hline & $\begin{array}{l}\text { Normal weight } \\
n=32\end{array}$ & $\begin{array}{c}\text { Overweight } \\
n=18\end{array}$ & $\begin{array}{c}\text { Obese } \\
n=11\end{array}$ & $\mathbf{P}^{*}$ \\
\hline $\operatorname{BMI}\left(\mathrm{kg} / \mathrm{m}^{2}\right)$ & $17.4 \pm 1.8$ & $22.4 \pm 2.5$ & $25.7 \pm 3.2$ & 0.000 \\
\hline $\begin{array}{c}\text { Frequency of crises in } \\
3 \text { months }\end{array}$ & $5(3-12)$ & $7(3-12)$ & $6(3-15)$ & 0.509 \\
\hline \multicolumn{5}{|l|}{ Severity ${ }^{* *}$} \\
\hline $0-4$ & $18(58.0 \%)$ & $2(11.1 \%)$ & $0(0 \%)$ & \multirow{3}{*}{0.212} \\
\hline 5-7 & $7(22.5 \%)$ & $7(38.8 \%)$ & $7(63.6 \%)$ & \\
\hline $8-10$ & $6(19.3 \%)$ & $9(50.0 \%)$ & $6(54.5 \%)$ & \\
\hline \multicolumn{5}{|l|}{ PedMIDAS $^{*}$} \\
\hline 1 & $20(64.5 \%)$ & $14(77.8 \%)$ & $7(63.6 \%)$ & \multirow{3}{*}{0.425} \\
\hline 2 & $10(32.3 \%)$ & $2(11.1 \%)$ & $3(27.3 \%)$ & \\
\hline 3 & - & $2(11.1 \%)$ & $1(9.1 \%)$ & \\
\hline 4 & $1(3.2 \%)$ & - & - & \\
\hline $\begin{array}{l}\text { PedsQL (average } \\
\text { score) }\end{array}$ & $74.7 \pm 13.6$ & $76.0 \pm 7.6$ & $71.0 \pm 15.7$ & 0.335 \\
\hline
\end{tabular}

BMI: Body mass index; PesdQL: Paedriatrics Score Quality of Life [13]; PedMIDAS: Pediatrics Migraine Disability Assessment. Severity was measured by a visual analogue scale of pain. The data are expressed as the mean \pm standard deviation, median and interquartile ranges (P25-P75) and frequency and percentage. ${ }^{*}$ ANOVA to compare means, Mann-Whitney test for medians and chi-square test for associations. ${ }^{* *} \mathrm{n}=31$ to normal weight category.

Table 2: Quality of life and characteristics of migraine in students, according to BMI classification 


\section{Discussion}

Recent studies have shown a varying prevalence of migraine in students. $[3,7,16,17]$ According to the latest data from the IBGE [17] there is high prevalence of overweight children and adolescents in Brazil. Among 5- to 9-year-old children, the prevalence of obesity is $16.6 \%$ and $11.1 \%$ for boys and girls, respectively, whereas for overweight adolescents these rates increase to $21.5 \%$ for boys and $32 \%$ for girls. In our study $39.8 \%$ of the sample was classified as overweight, according to BMI, which was a larger percentage than the reference values for the population.

Few studies have addressed the relationship between obesity and migraine in children and adolescents. [16,18,19] Robberstad et al. (2010) [20] showed a correlation between migraine and obesity, which was absent in our study. Although a high percentage of migraineurs were overweight, this prevalence in our study was found to be below that reported in a recent study [18], in which $68.2 \%$ of children and adolescents with migraine were classified as being overweight or at risk for obesity.

Kinik et al. (2010) [16] showed also found no association between the severity of migraine crises and the nutritional status, similar to what we observed in the present study. However, these authors [16], showed a positive correlation between BMI and the number of migraine crises. In another study, there were no differences between the BMI levels in children and adolescents with migraine and those of the overall population [19].

Studies have separately demonstrated the relationships between migraine or obesity and a decreased QL [2,21], suggesting that these factors could overlap, further reducing QL. However, in the present study, the overweight students did not differ from normal weight students in regards to the QL score, which could be attributed to the fact that the level of disability generated by migraine crises was also not different among the different classes of nutritional status. We must also consider that most of the students scored a low degree of disability when assessed by PedMIDAS [11], demonstrating that the level of disability generated by migraine crises by subjects in the present study may not result in a decreased QL. On the other hand, we observed that a high percentage of obese students had higher severity scores. Although no association between the nutritional status and severity of attacks was found, it can be observed that, among the few obese children and adolescents, approximately 50\% showed elevated severity values according to the visual analogue scale. Despite this finding, the data set does not ratify the relationships between being overweight/obese and the level of disability generated by migraine crises, migraine severity, or QL.

Because the data were collected in a school population, it is believed that the PedMIDAS [11] scores and obtained data regarding the severity of migraine crises were not as pronounced as they would be for children and adolescents receiving prophylactic treatment and monitoring in hospitals. The same limitation could explain the lack of association between the nutritional status and QL.

\section{Conclusion}

Among the studied students that reported headache, although there was a high percentage of overweight students who reported migraine in our sample, analyses show no associations between the nutritional status, evaluated through BMI, and , migraine frequency, migraine severity, disability generated by the migraine crises, or QL.

\section{Acknowledgment}

The authors thank all of the students who participated in the survey, as well as those responsible for the schools for their efforts and collaboration in the organization of data collection. This study received financial support from FIPE/HCPA (Fundo de Incentivo à Pesquisa/Hospital de Clínicas de Porto Alegre) and research grants from FAPERGS and Propesq/UFRGS.The evaluation of QL in this study was accomplished using the PedsQL TM, developed by Dr. James W. Varni.

\section{References}

1. International Headache Society (IHS) (2004) The International Classification of Headache Disorders.Cephalalgia 24: 9-160.

2. Rocha-Filho PA, Santos PV (2014) Headaches, Quality of Life, and Academic Performance in Schoolchildren and Adolescents. Headache 54: $1194-202$.

3. Abu-Arafeh I, Razak S, Sivaraman B, Graham C (2010) Prevalence of headache and migraine in children and adolescents: a systematic review of populationbased studies. Dev Med Child Neurol 52: 1088-97.

4. Laurell K, Larsson B, Eeg-Olofsson O (2004) Prevalence of headache in Swedish schoolchildren, with a focus on tension-type headache. Cephalalgia 24: 380-8.

5. Lipton RB, Bigal ME, Diamond M, FreitagF, Reed ML, et al. (2007) Migraine prevalence, disease burden, and the need for preventive therapy. Neurology 68: 343-9.

6. Guidetti V, Galli F (1998) Evolution of headache in childhood and adolescence: an 8-year follow-up. Cephalalgia 18: 449-54.

7. Hershey AD, Powers SW, Nelson TD, Kabbouche MA, Winner P, et al. (2009) Obesity in the pediatric headache population: a multicenter study. Headache 49: $170-7$.

8. Milde-Busch A, Boneberger A, Heinrich S, Thomas S, Kühnlein A, et al. (2010) Higher prevalence of psychopathological symptoms in adolescents with headache. A population-based cross-sectional study. Headache 50: 738-48. 
9. Hershey AD, Powers SW, Vockell AL, LeCates S, Kabbouche M (2002) Effectiveness of topiramate in the prevention of childhood headaches. Headache 42: 810-8.

10. ABEP - Associação Brasileira de Empresas de Pesquisa (2011) - Critério de Classificação Econômica Brasil.

11. Hershey AD, Powers SW, Vockell AL, LeCates S, Kabbouche MA, et al. (2001) PedMIDAS: development of a questionnaire to assess disability of migraines in children. Neurology 57: 2034-9.

12. Varni JW, Limbers CA (2009) The pediatric quality of life inventory: measuring pediatric health-related quality of life from the perspective of children and their parents. Pediatr Clin North Am 56: 843-63.

13. Varni JW, Seid M, Rode CA (1999) The PedsQL: measurement model for the pediatric quality of life inventory. Med Care 37: 126-39.

14. WHO (2011) AnthroPlus for personal computers Manual: Software for assessing growth of the world's children and adolescents. Geneva, Switzerland.

15. WHO (2011) World Health Organization.Department of Nutrition.WHO Anthro Plus v. 1.0.4 and macros. Geneva, Switzerland.

16. Kinik ST, Alehan F, Erol I, Kanra AR (2010) Obesity and paediatric migraine. Cephalalgia 30: 105-9.

17. BRASIL (2010) IBGE. IntitutoBrasileirode Geografia e Estatística.

18. Verrotti A, Di Fonzo A, Agostinelli S, Coppola G, Margiotta M, et al. (2012) Obese children suffer more often from migraine. Acta Paediatr 101: 416-21.

19. Pinhas-Hamiel O, Singer S, Pilpel N, Fradkin A, Modan D, et al. (2006) Health-related quality of life among children and adolescents: associations with obesity. Int J Obes (Lond) 30: 267-72.

20. Robberstad L, Dyb G, Hagen K, Stovner LJ, Holmen TL, et al. (2010) An unfavorable lifestyle and recurrent headaches among adolescents: the HUNT study. Neurology 75: 712-7.

21. Milde-Busch A, Heinrich S, Thomas S, Kühnlein, A, Radon K, et al. (2010) Quality of life in adolescents with headache: results from a population-based survey. Cephalalgia 30: 713-21. 